\title{
Avaliação da solução de pulsing com ácido giberélico \\ na vida de vaso de Heliconia bihai ${ }^{(1)}$
}

\author{
ADRIANA ANDRADE GUIMARÃES (2), FERNANDO LUIZ FINGER (2), \\ TANIA PIRES DA SILVA ${ }^{(3)}$, JOSÉ GERALDO BARBOSA (2)
}

\begin{abstract}
RESUMO
O jasmim-manga (Plumeria spp.) é uma planta muito utilizada na ornamentação urbana, principalmente por sua rusticidade, fácil manejo e exuberância de suas flores. Folhas de Plumeria spp. foram coletadas no município de Dourados, MS, com sintomas e sinais típicos da presença de ferrugem: uredinias pulverulentas de coloração amarelada na face abaxial e manchas cloróticas e necróticas, na face adaxial das folhas, culminando algumas vezes com abscisão foliar. O presente trabalho tem por objetivo registrar a ocorrência da doença no Estado de Mato Grosso do Sul. Observações microscópicas e mensurações de urediniosporos e teliosporos confirmaram a presença do fungo Coleosporium plumeriae infectando essas plantas.
\end{abstract}

Palavras-chave: Coleosporium plumeriae, jasmim-manga.

\section{ABSTRACT}

Rust in Plumeria spp. (Apocynaceae) in the state of Mato Grosso do Sul, Brazil.

Frangipani (Plumeria spp.) is a plant widely used in urban ornamentation, due to its hardiness, easy handling and exuberance of its flowers. Plumeria spp. Leaves were collected in Dourados, MS, Brazil, with typical symptoms and signs of the presence of rust: powdery yellowish uredinias in the abaxial and chlorotic and necrotic spots on the adaxial surface of the leaves, sometimes resulting in leaf abscission. The present study aims to record the occurrence of the disease in the State of Mato Grosso do Sul. Microscopic observations and measurements of uredinospores and teliospores confirmed that the fungus infecting plants was Coleosporium plumeriae.

Keywords: Coleosporium plumeriae, Frangipani.

\section{INTRODUÇÃO}

As helicônias são espécies de flores que tem despertado grande interesse no mercado interno e externo, por apresentarem ampla diversidade de cores, forma e tamanho, produção de flores contínua e em grande quantidade, resistência ao transporte (ALONSO, 2009; CASTRO, 1995). Assim, podem ser utilizadas tanto como flores de corte bem como plantas de jardim. As brácteas são vistosas, normalmente têm intenso e exuberante colorido, com cores contrastantes, característica que favorece a sua aceitação pelo consumidor (CASTRO et al., 2007). No entanto, apesar de algumas espécies serem consideradas rústicas, há poucos registros na literatura do comportamento da vida de vaso dessas espécies.

Uma das técnicas utilizadas no retardo da senescência foliar e floral é a aplicação de reguladores de crecimento, como auxinas, citocininas e giberelinas (PHILOSOPH-HADAS et al., 1996). Dentre os reguladores, o ácido giberélico $\left(\mathrm{GA}_{3}\right)$ tem sido bastante utilizado por se mostrar um potente inibidor da senescência foliar e floral de várias espécies. No entanto, a eficiência da aplicação desse regulador como de outros varia conforme a concentração, forma de aplicação, época e sensibilidade dos tecidos ao regulador. Adicionalmente, o mecanismo fisiológico da ação do ácido giberélico sobre os efeitos no retardo da senescência dos produtos hortícolas permanece ainda desconhecido. Uma possibilidade é a alteração do equilíbrio natural dos reguladores de crescimento endógenos (FERRANTE e FRANCINI, 2006).
Há alguns registros na literatura que relatam efeitos positivos do $\mathrm{GA}_{3}$ sobre a longevidade pós-colheita de algumas flores, como em Zantedeschia elliottiana, cujo tratamento com 50 e $100 \mathrm{mg} \mathrm{L}^{-1}$ de $\mathrm{GA}_{3}$, promoveu menores perdas de massa quando comparada a hastes mantidas em água destilada (JANOWSKA e JERZY, 2004). Quando o $\mathrm{GA}_{3}$ foi aplicado a $100 \mathrm{mg} \mathrm{L}^{-1}$ de $\mathrm{GA}_{3}$ em hastes de priprioca (Cyperus articulatus), como pulsing por 24 horas associado à hidratação, imediatamente após a colheita, prolongou a durabilidade comercial em mais de $60 \%$ quando comparado ao controle (ROBLES et al., 2007). Porém não são encontrados na literatura trabalhos com o uso de ácido giberélico em hastes de Heliconia bihai.

Assim, o objetivo desse trabalho foi verificar a influência de duas doses de ácido giberélico aplicado na forma de solução de pulsing na vida de vaso de hastes de Heliconia bihai.

\section{MATERIAL E MÉTODOS}

Hastes florais de Heliconia bihai oriundas de propriedade comercial, localizada no Estado do Ceará, foram colhidas em outubro de 2006, às $7 \mathrm{~h}$ da manhã, com três a quatro brácteas abertas mais o ponteiro. No laboratório, as hastes foram padronizadas em $70 \mathrm{~cm}$ de comprimento e hidratadas por $15 \mathrm{a}$ 20 minutos em baldes contendo água destilada. Em seguida, as hastes foram mantidas em solução de pulsing com ácido giberélico $\left(\mathrm{GA}_{3}\right)$ nas concentrações de 50 e $100 \mathrm{mg} / \mathrm{L}$ durante seis horas. Hastes controle foram mantidas em água destilada.

\footnotetext{
(1) Trabalho recebido para publicação em 03/08/2013 e aprovado em 12/02/2014

(2) Universidade Federal de Viçosa - UFV, Departamento de Fitotecnia, Viçosa-MG E-mail: ffinger@ufv.br

${ }^{(3)}$ Estudante de pós-doutorado, Universidade Federal de Viçosa - UFV, Departamento de Fitotecnia, Viçosa-MG
} 
Após o tratamento de pulsing, as hastes foram transferidas para baldes contendo água destilada por até 12 dias, mantidas em temperatura ambiente a $25 \pm 2^{\circ} \mathrm{C}$, umidade relativa de 60 $80 \%$, e intensidade luminosa de $5 \mathrm{mmol} \mathrm{m}^{-2} \mathrm{~s}^{-1}$. A cada 48 horas, foi efetuada a troca da água dos vasos com o intuito de evitar a proliferação de microrganismos, além do corte de cerca de 2,0 $\mathrm{cm}$ da base da haste.

A aparência visual das hastes foi realizada diariamente com auxílio de escala de notas subjetiva. A nota 3 foi destinada às hastes que não apresentavam nenhum sintoma de murcha e/ ou descoloração e escurecimento de brácteas e pecíolo das folhas; 2 = incidência de 10 a $30 \%$ de murcha e/ou descoloração do pecíolo das folhas e brácteas; $1=40$ a $50 \%$ murcha e/ou descoloração do pecíolo das folhas e brácteas e $0=\geq 50 \%$ murcha e/ou descoloração do pecíolo das folhas e brácteas (nota de descarte). A longevidade floral compreendeu o número de dias entre a colheita até $50 \%$ das hastes florais obterem a nota de descarte.

Foi avaliada a cada dois dias a perda de massa, sendo obtida e calculada da seguinte maneira:

Perda de massa $=\underline{(\mathrm{M} \mathrm{S} / \mathrm{C}-\mathrm{M} \mathrm{C} / \mathrm{C})} 100$

$\mathrm{P} \mathrm{C} / \mathrm{C}$

$\mathrm{M} \mathrm{S} / \mathrm{C}$ : massa fresca das hastes antes do corte.

$\mathrm{M} \mathrm{C/C}$ : massa fresca das hastes após o corte. Os resultados foram expressos em $\%$.

O Teor Relativo de Água das Brácteas (TRA B) e Pseudocaule (TRA P) foi realizado a cada três dias, conforme metodologia proposta por Catsky (1974) e Weatherley (1950), e os resultados expressos em \%. O conteúdo de antocianina foi determinado a cada três dias, conforme metodologia proposta por Markakis (1982), o conteúdo de antocianinas foi medido em espectrofotômetro a $535 \mathrm{~nm}$ e os resultados expressos em mg de antocianina por massa de matéria fresca. A atividade enzimática da peroxidase e da polifenoloxidase foi determinada a cada dois dias conforme metodologia proposta por Matsuno e Uritani (1972) e Wissemann e Lee (1980), os resultados foram expressos em DUA/min/mg de proteína. Para a quantidade de proteína utilizou-se o método de Bradford (1976), usando Soro Albumina Bovina (BSA) como padrão.

$\mathrm{O}$ experimento foi conduzido em delineamento inteiramente casualizado em esquema de parcelas subdivididas no tempo, tendo nas parcelas as três concentrações de ácido giberélico e na subparcela os seis períodos de armazenamento, com três repetições de três hastes para cada tratamento em cada tempo. Os dados foram analisados por meio de análise de variância a $5 \%$ de significância e regressão através do teste " $\mathrm{t}$ ".

\section{RESULTADOS E DISCUSSÃO}

Baseado nas notas da aparência visual, a longevidade floral de hastes de Heliconia bihai foi estimada em 7 dias para a testemunha e de 9 dias para hastes tratadas com o ácido giberélico, promovendo, portanto, aumento de $20 \%$ na longevidade comparado às hastes não tratadas (Figura 1) . De acordo com Castro (1993), helicônias que apresentam longevidade menor ou igual a 7 dias são classificadas como curtas, de 8 a 14 dias como média e acima de 14 dias como de longevidade alta.

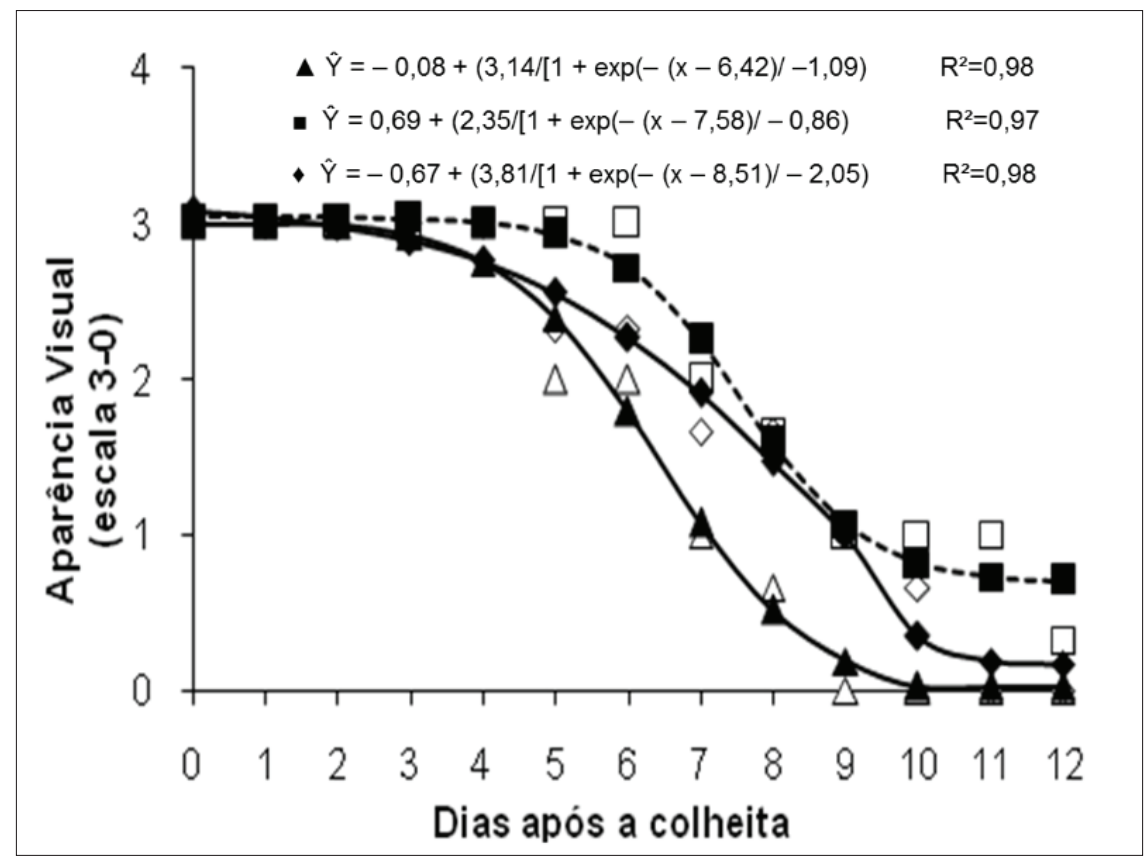

Figura 1: Aparência visual de hastes de Heliconia bihai submetidas à solução de pulsing com ácido giberélico: $\boldsymbol{\Delta} 0$; 50 e $100 \mathrm{mg} \mathrm{L-1}$ e armazenadas por 12 dias a $25 \pm 2^{\circ} \mathrm{C}$ e umidade relativa de $60-80 \%$.

Figure 1: Visual appearance of stems of Heliconia bihai subjected to pulsing solution with gibberellic acid: - 0; 50 and $100 \mathrm{mg} \mathrm{L-1}$ and stored for 12 days at $25 \pm 2{ }^{\circ} \mathrm{C}$ and relative humidity of $60-80 \%$. 
O decréscimo na aparência visual das hastes foi decorrente do surgimento de manchas escuras no tecido das brácteas, além do amarelecimento e ressecamento da ponta das brácteas e pecíolo das folhas. Essas manchas escuras na superfície das brácteas foram atribuídas à antracnose, doença comum em helicônias, cujos sintomas, segundo Assis et al. (2002), são manchas de colorações que variam conforme a espécie.

A percentagem de perda de massa verificada nesse experimento não promoveu sintomas de murcha no tecido das brácteas, porém, sinais de ressecamento na ponta das brácteas e pecíolo das folhas foram constatados, afetando a aparência visual das flores (Figura 2).

De algum modo o uso do ácido giberélico, nas duas concentrações utilizadas, interferiu negativamente na absorção de água pelos tecidos das brácteas, uma vez que hastes do controle apresentaram maiores valores de TRA para as brácteas (Figura 3), embora a causa para esse resultado seja de natureza desconhecida.

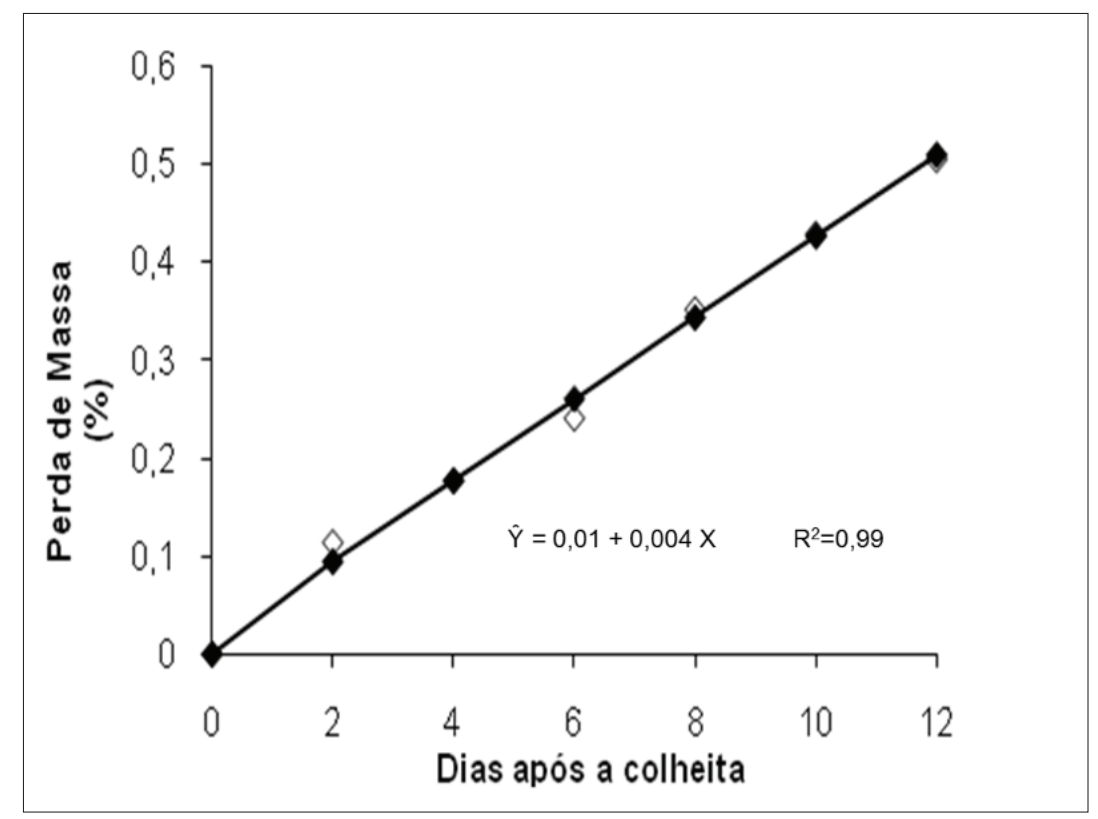

Figura 2: Perda de massa fresca em hastes de Heliconia bihai, armazenadas a $25 \pm 2^{\circ} \mathrm{C}$ e umidade relativa de $60-80 \%$.

Figure 2: Weight loss of stems of Heliconia bihai stored at $25 \pm 2^{\circ} \mathrm{C}$ and relative humidity of $60-80 \%$.

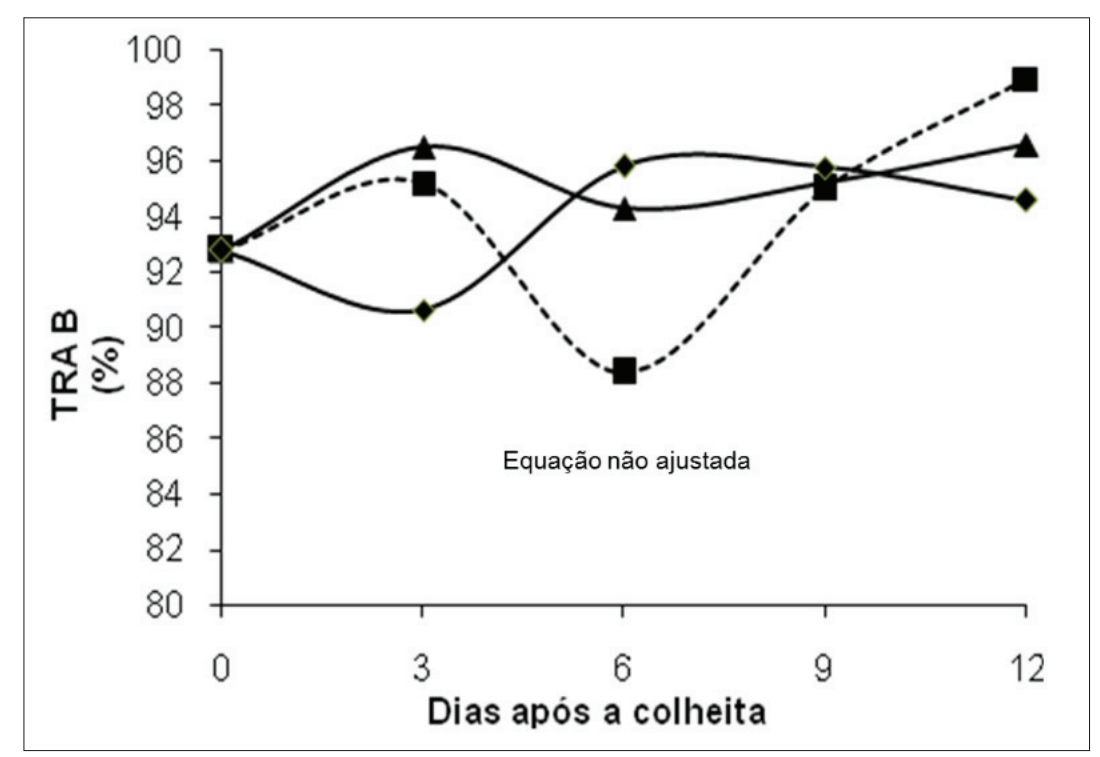

Figura 3: Teor Relativo de água das brácteas (TRA B) de hastes de Heliconia bihai submetidas à solução de pulsing com ácido giberélico: $\Delta$ 0; 50 e $100 \mathrm{mg} \mathrm{L}-1$ e armazenadas por 12 dias a $25 \pm 2{ }^{\circ} \mathrm{C}$ e umidade relativa de $60-80 \%$. Figure 3: Relative water content in bracts (TRA B) of Heliconia bihai stems subjected to pulsing solution with gibberellic acid: $\Delta$ 0; 50 and $100 \mathrm{mg} \mathrm{L-1}$ and stored for 12 days at $25 \pm 2^{\circ} \mathrm{C}$ and relative humidity of 60-80\%. 


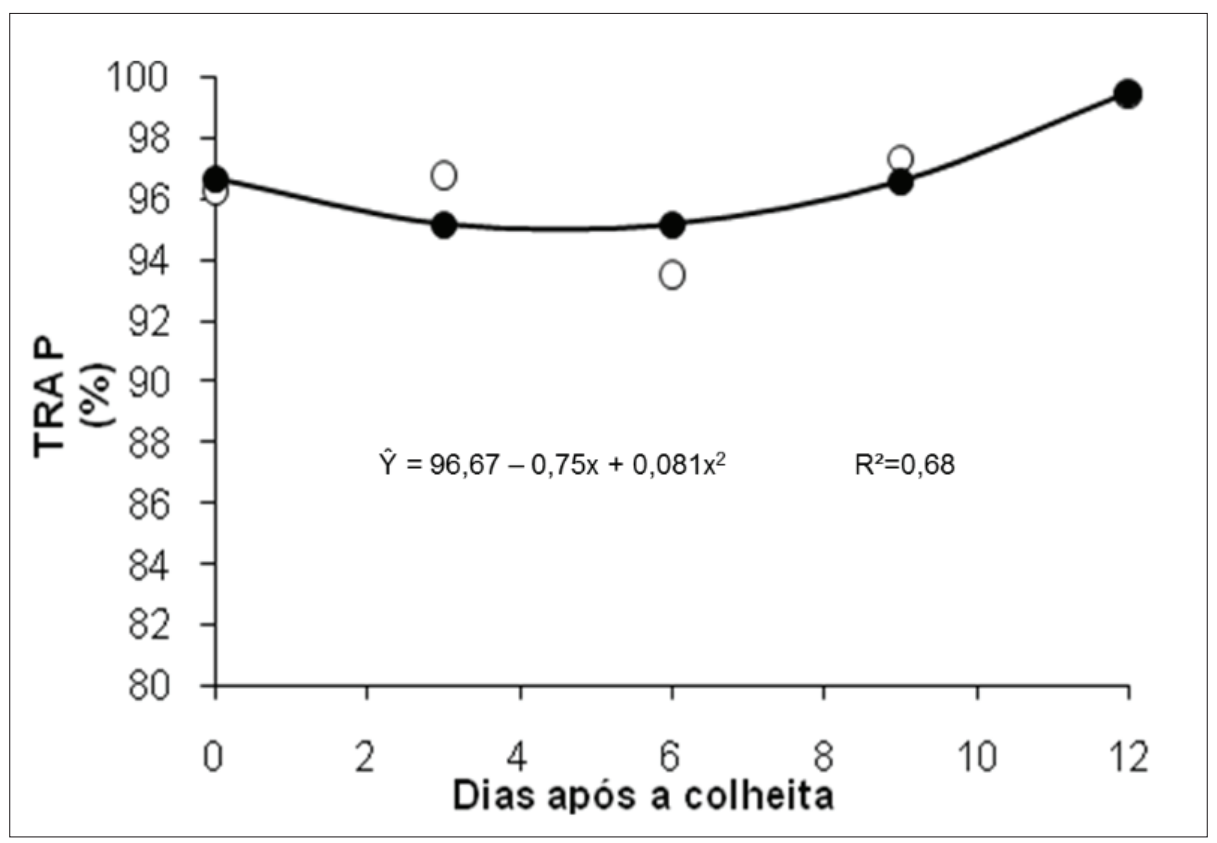

Figura 3: Teor Relativo de água das brácteas (TRA B) de hastes de Heliconia bihai submetidas à solução de pulsing com ácido giberélico: $\boldsymbol{\Delta}$ 0; $\mathbf{\square} 50$ e $100 \mathrm{mg} \mathrm{L}-1$ e armazenadas por 12 dias a $25 \pm$ $2{ }^{\circ} \mathrm{C}$ e umidade relativa de $60-80 \%$.

Figure 3: Relative water content in bracts (TRA B) of Heliconia bihai stems subjected to pulsing solution with gibberellic acid: $\mathbf{\Delta} 0$; $\boldsymbol{\square} 50$ and $100 \mathrm{mg} \mathrm{L-1}$ and stored for 12 days at $25 \pm 2{ }^{\circ} \mathrm{C}$ and relative humidity of $60-80 \%$.

O teor relativo de água no pseudocaule não apresentou diferença entre os tratamentos utilizados, mostrando maior efeito do $\mathrm{GA}_{3}$ nas brácteas das hastes de helicônias (Figura 4). Em crisântemos cv 'Chá Repin', a utilização de ácido giberélico $\left(\mathrm{GA}_{3}\right)$ na concentração de $20 \mathrm{mg} \mathrm{L}^{-1}$ e sacarose, bem como a mistura de $\mathrm{GA}_{3}$ e sacarose, promoveu a aceleração da senescência tanto em folhas como nas flores de crisântemos (SANCHES LASCHI, 2007).
$\mathrm{O}$ uso de $\mathrm{GA}_{3}$ não apresentou diferença na atividade das enzimas peroxidase (Figura 5) e polifenoloxidase (Figura 6). O decréscimo na atividade de ambas as enzimas, verificado nesse experimento, pode ser atribuído à diminuição dos compostos fenólicos que atuam como substrato nas reações de escurecimento promovidas por essas enzimas.

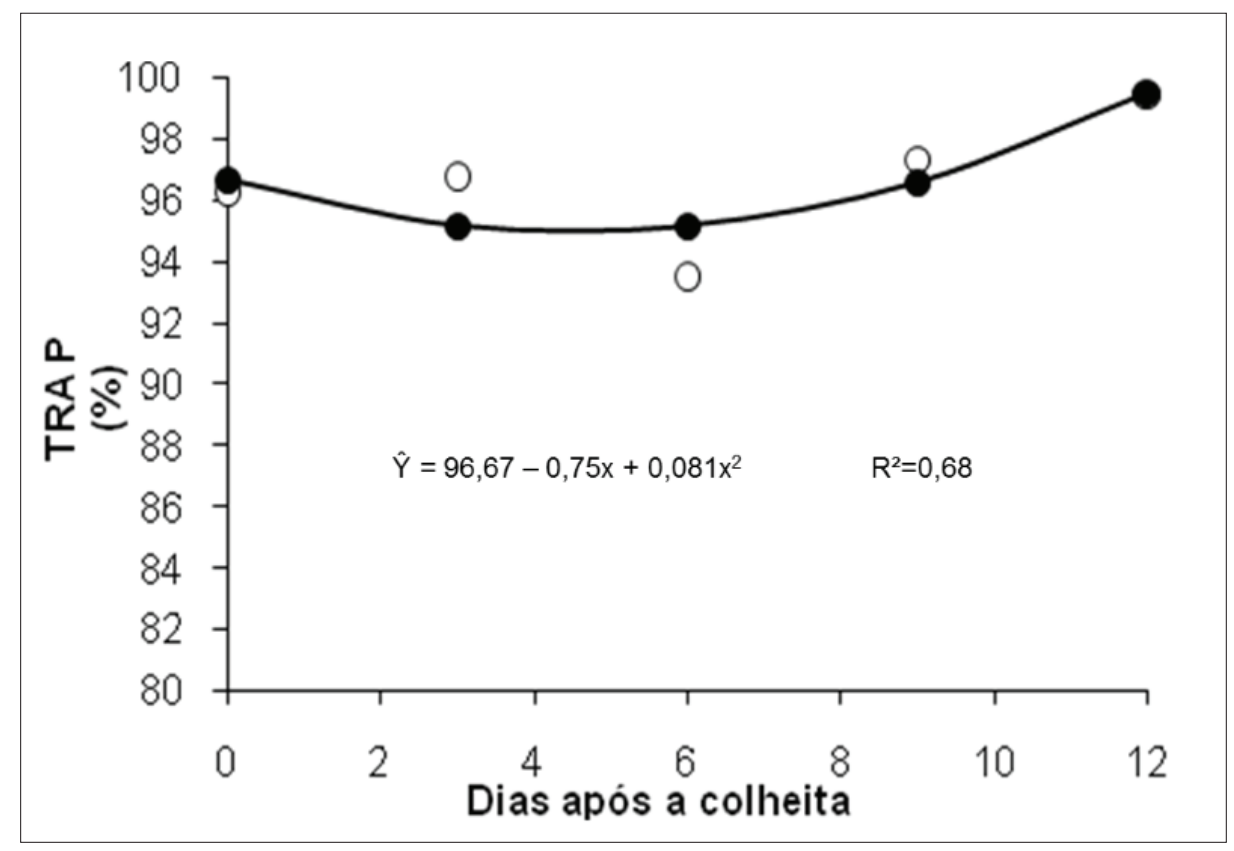

Figura 4: Teor relativo de água do pseudocaule (TRA P) de hastes de Heliconia bihai, armazenadas a $25 \pm 2^{\circ} \mathrm{C}$ e umidade relativa de $60-80 \%$.

Figure 4: Relative water content of pseudostem (TRA P) of stems Heliconia bihai stored at $25 \pm 2^{\circ} \mathrm{C}$ and relative humidity of $60-80 \%$. 


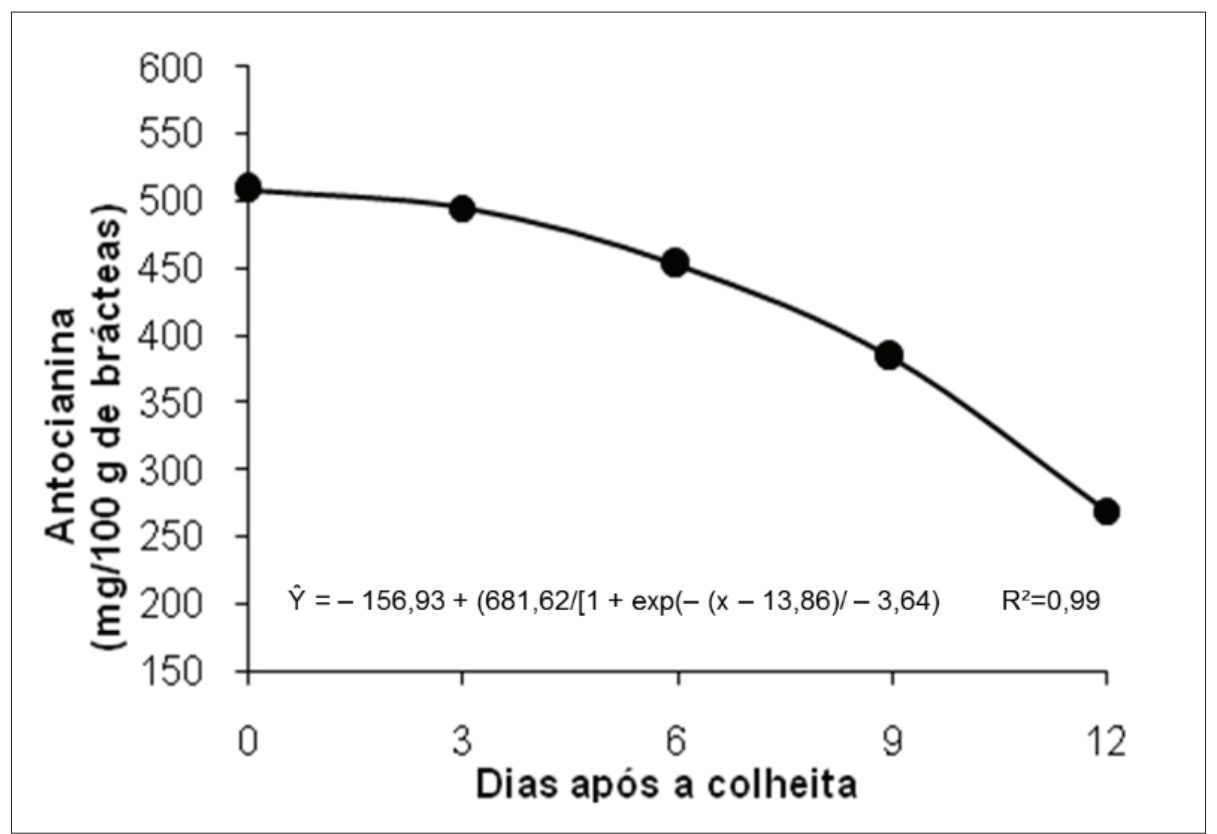

Figura 5: Estimativas da concentração de antocianina em hastes Heliconia bihai, armazenadas por 12 dias a $25 \pm 2{ }^{\circ} \mathrm{C}$ e umidade relativa de $60-80 \%$.

Figure 5: Estimation of the anthocyanin concentration in stems Heliconia bihai, stored for 12 days at $25 \pm 2^{\circ} \mathrm{C}$ and relative humidity of $60-80 \%$.

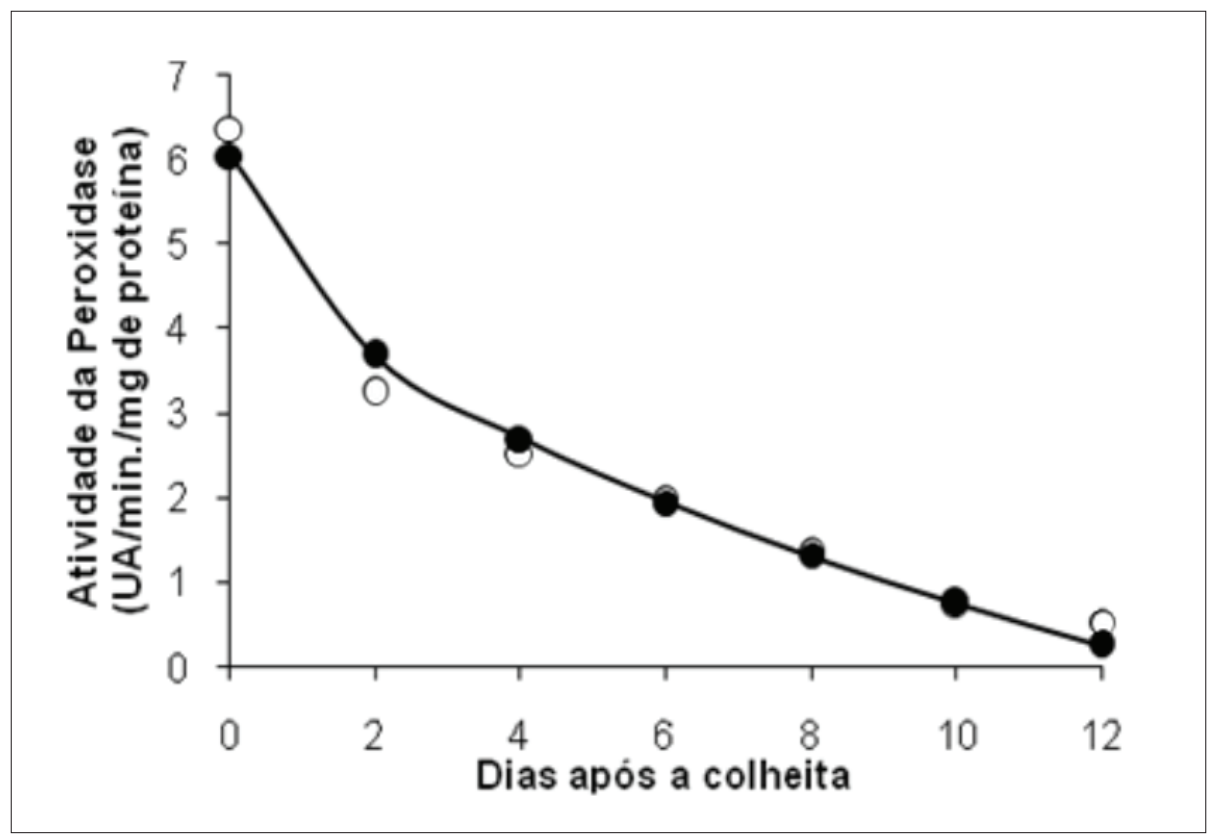

Figura 6: Atividade da peroxidase de hastes de Heliconia bihai, armazenadas a $25 \pm 2^{\circ} \mathrm{C}$ e umidade relativa de $60-80 \%$.

Figure 6: Peroxidase activity in Heliconia bihai stems stored at $25 \pm 2{ }^{\circ} \mathrm{C}$ and relative humidity of $60-80 \%$.

Para o conteúdo de antocianinas não houve diferença entre os tratamentos, entretanto, houve um comportamento decrescente no conteúdo de antocianinas em função dos períodos de armazenamento das hastes de helicônia (Figura 7). Chegando a $47 \%$ de perda de pigmentos no final do experimento em relação aos valores na ocasião da colheita das hastes. Normalmente, durante o murchamento das pétalas, as membranas celulares progressivamente perdem sua integridade, resultando no extravasamento de pigmentos dentre eles as antocianinas (RUBINSTEIN, 2000). 


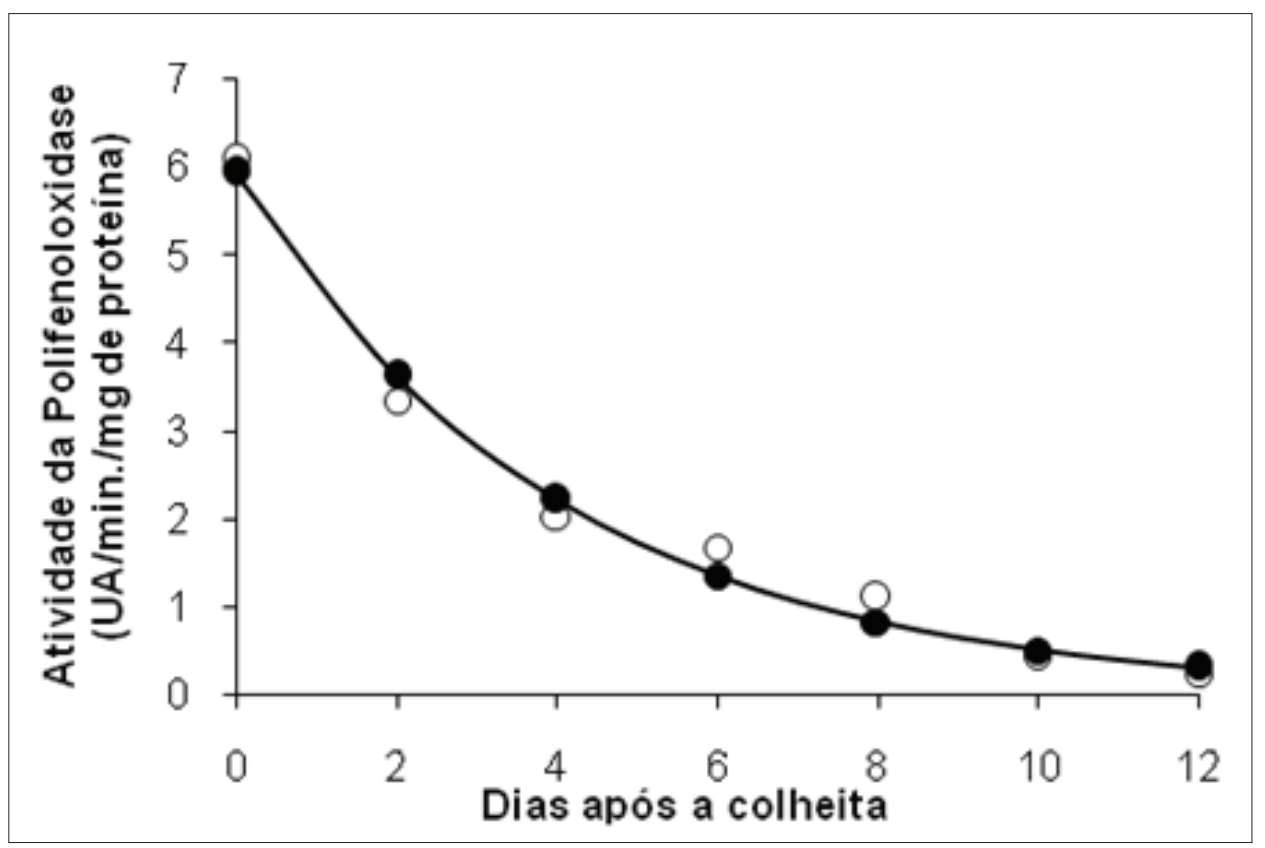

Figura 7: Estimativa da atividade da polifenoloxidase em hastes Heliconia bihai, armazenadas por 12 dias a $25 \pm 2^{\circ} \mathrm{C}$ e umidade relativa de $60-80 \%$.

Figure 7: Estimation of the polyphenol oxidase activity in stems Heliconia bihai, stored for 12 days at $25 \pm 2^{\circ} \mathrm{C}$ and relative humidity of $60-80 \%$.

Ao contrário dos resultados obtidos nesse experimento, o ácido giberélico tem promovido a manutenção da coloração de flores e folhas de várias espécies ornamentais. Dentre elas o híbrido Santonia (Sandersonia aurantiaca x Littonia modesta), onde o tratamento com ácido giberélico preservou a coloração das flores, sem sinais de clorose foliar durante 12 dias de vida de vaso (EASON et al., 2001). Folhas de Alstroemeria também responderam positivamente ao tratamento com ácido giberélico, o teor de clorofila nas folhas tratadas permaneceu mais alto quando comparado ao tratamento controle (FERRANTE et al., 2001).

As antocianinas também podem ser degradadas por enzimas endógenas presentes nos tecidos das plantas, tais como glicosidases, polifenol oxidases e peroxidases, pois atuam sobre compostos fenólicos, causando a sua oxidação a quinonas na presença de $\mathrm{O}_{2}$ (VAUGHN e DUKE, 1984), com escurecimento dos tecidos devido à polimerização delas ou a sua reação com aminoácidos e proteínas.

Os substratos usuais da PPO incluem os ésteres dos ácidos cinamicos, como o ácido clorogenico, as catequinas, a 3,4-dihidroxifenilalanina (DOPA) e a tirosina. Por atuarem em conjunto com as glicosidases, podem também causar o escurecimento em produtos ricos em antocinaninas através da produção de quinonas correspondentes. As quinonas resultantes da oxidação dos fenólicos apresentam coloração vermelha a marrom-avermelhada, entretanto, a subsequente polimerização dessas gera macromoléculas mais escuras. Desta forma, o escurecimento enzimático dos tecidos vegetais depende não só do tipo de substrato, concentração e localização, como também do tipo de polímero formado a partir da quinona (CHITARRA e CHITARRA, 2005).

Resultados contrários aos verificados no presente experimento foram encontrados em Myrica rubra Bieb., onde o tratamento com ácido giberélico durante a indução dos botões florais inibiu significativamente à atividade das enzimas peroxidase e polifenoloxidase (LI et al., 2003).

Aplicação de $\mathrm{GA}_{3}(100$ e $250 \mu \mathrm{M})$, na forma de pulsing por $24 \mathrm{~h}$, reduziu significativamente a vida de vaso de folhagem de corte da espécie Dracaena deremensis (SUBHASHINI et al., 2011). Houve redução da vida pós-colheita das flores e folhas de cravo, de acordo com Cywinska-Smoter et al. (1978), que relataram uma diminuição da longevidade das flores e descoloração das folhas. Doi e Reid (1995), com o híbrido limonium, e Hutchinson et al. (2003), com flores tuberosas cortadas, também mostraram que giberelinas não têm efeito na vida de vaso.

Por outro lado, giberelinas $\left(\mathrm{GA}_{3}\right)$ mostrou retardar o amarelecimento das folhas em Alstroemeria (MUTUI et al., 2006) e em lírios (RANWALA et al., 2003), aumentou a vida de vaso e massa fresca flores de gérberas (DANAEE et al., 2011). Estes dados indicam que os reguladores de crescimento de plantas têm efeitos variáveis na qualidade pós-colheita de espécies de plantas diferentes (BOSSE e VAN STADEN, 1989). Não se sabe o que causa os efeitos variáveis das giberelinas. Uma possibilidade é que a aplicação exógena de reguladores de crescimento sinteticos pode alterar o equilíbrio natural de reguladores de crescimento endógenos, induzindo uma tensão de acordo com a espécie de planta e do órgão em estudo (FERRANTE e FRANCINI, 2006).

\section{CONCLUSÕES}

O ácido giberélico nas concentrações e forma utilizadas não influenciou a perda demassa, teor relativo deágua do pseudocaule, antocianina, atividade da peroxidase e polifenoloxidase, porém, apresentou efeito positivo na aparência visual. 
Baseado nas notas da aparência visual, a longevidade floral de hastes de Heliconia bihai foi estimada em 7 dias para a testemunha e de 9 dias para hastes tratadas com o ácido giberélico.

\section{AGRADECIMENTOS}

Ao Conselho Nacional de Desenvolvimento Científico e Tecnológico (CNPq) e à EMBRAPA Agroindústria Tropical.

\section{REFERÊNCIAS}

ALONSO, A.M.; SOUSA-SILVA, J.C. Heliconia angusta Vell.: caracterização de uma planta ornamental para cultivo no Cerrado. Planaltina, DF: Embrapa Cerrados, 2009. 24p. (Embrapa Cerrado. Documentos, 272).

ASSIS, S.M.P.; MARIANO, R.R.L.; GONDIM JÚNIOR, M.G.C.; MENEZES, M.; ROSA, R.C.T. Doenças e pragas das helicônias. UFRPE. Recife-PE, 2002. 120 p.

BOSSE, A.; VAN STADEN, J. Cytokinins in cut carnation flowers. Effect of cytokinin type, and mode of application on flower longevity. Journal of Plant Physiology, Paris, v.135, p.155-159, 1989.

BRADFORD, M.A. A rapid and sensitive method for the quantification of microgram quantities of protein utilizing the principle of protein-dye binding. Analytical Biochemistry, London, v.72, p.248-254, 1976.

CASTRO, C.E.F. de. Helicônias como flores de corte: adequação de espécies e tecnologia pós-colheita. Piracicaba: ESALQ, 1993. 191p. (Tese de Doutorado).

CASTRO, C.E.F. de. Heliconia para exportação: aspectos técnicos da produção. Brasília: MAARA-SDR/EMBRAPASPI. 43p. il. (Série Publicações Técnicas FRUPEX, 16). 1995.

CASTRO, C.E.F.; MAY, A.; GONÇALVES, C. Espécies de helicônia como flores de corte. Revista Brasileira de Horticultura Ornamental, Campinas, v.12, n.2, p.87-96, 2007.

CATSKY, J. Water content In: SLAVIK, B. Methods of studying plant water relations. Berlin, Springer-Verlang, p.121-131,1974.

CYWINSKA-SMOTER, K.; RUDNICKI R.M.; GOSZCZYNSKA, D. The effect of exogenous regulation in opening tight carnation buds. Scientia Horticulturae, Amsterdan, v.9, p.155-165, 1978.

DANAEE, E.; MOSTOFI, Y.; MORADI, P. Effect of GA And $_{3}$ BA on Postharvest Quality and Vase Life of Gerbera (Gerbera jamesonii. cv. Good Timing) Cut Flowers. Horticulture, Environment and Biotechnology, London, v.52, p.140-144, 2011.
DOI, M.; REID, M.S. Sugar improves the postharvest life of cut flowers of hybrid Limonium. Horticultural Science, Praha, v.30, p.1058-1060, 1995.

EASON, J.R.; MORGAN, E.R.; MULLAN, A.C.; BURGE, G.K. Postharvest characteristics of Santonia 'Golden Lights' a new hybrid cut flower from Sandersonia aurantiaca x Littonia modesta. Postharvest Biology and Technology, Amsterdan, v.22, p.93-97, 2001.

FERRANTE, A.; FRANCINI, A. Ethylene and leaf senescence. In: Khan N.A. (Ed.), Ethylene action in plant. Springer Verlarg, Berlin, Heideberg. p.51-64, 2006.

FERRANTE, A.; HUNTER, D.A.; HACKETT, W. P.; REID, M.S. Thidiazuron-a potent inhibitor of leaf senescence in Alstroemeria. Postharvest Biology and Technology, Amsterdan, v.25, p.333-338, 2002.

HUTCHINSON, M.J.; CHEBET, D.K.; EMONGOR V.E. Effect of Accel, sucrose and silver thiosulphate on the water relation and postharvest physiology of cut Tuberose flowers. African Crop Science Journal, Kampala, v.11, p.279-287, 2003.

JANOWSKA, B; JERZY, M. Effect of gibberellic on the quality of cut flowers of Zantedeschia elliottiana (W. Wats.) Engl. Eletronic Journal of Polish Agricultural Universities, Wroclaw, v.7, n.2, Series Horticulturae, 2004.

LI, X.; LI, S.; LIN, J. Effect of $\mathrm{GA}_{3}$ spraying on lignin and auxin contents and the correlated enzyme activities in bayberry (Myrica rubra Bieb.) during flower-bud induction. Plant Science, New York, v.164, p.549-556, 2003.

MARKAKIS, P. Anthocyanins as food colors. New York: Academic Press, p.181-207, 1982.

MATSUNO, H.; URITANI, I. Physiological behavior of peroxidase isozymes in sweet potato root tissue injured by cutting or with black rot. Plant and Cell Physiology, Tokyo, v.13, p.1091-1101, 1972.

MUTUI, T.M.; EMNOGOR, V.E.; HUTCHINSON, M.J. The effects of gibberellins(4+7) on the vase life and flower quality of Alstroemeria cut flowers. Plant Growth Regulation, Amsterdan, v.48, p.207-214, 2006.

PHILOSOPH-HADAS, S.; MICHAELI, R.; REUVENI, Y; MEIR, S. Benzyladenine pulsing retards leaf yellowing and improves quality of goldenrod (Solidago Canadensis) cut flowers. Postharvest Biology and Technology, Amsterdan, v.9, p.65-73, 1996.

SANCHES, L. V.; LASCHI D. Efeito do ácido giberélico (GA) e sacarose em pós-colheita de crisântemo var. 'Chá Repin'. IN: $16^{\circ}$ CONGRESSO BRASILEIRO DE FLORICULTURA E PLANTAS ORNAMENTAIS, 2007, GOIÂNIA-GO. Resumos do $16^{\circ}$ Congresso Brasileiro de Floricultura e Plantas Ornamentais. Goiânia-GO: CD-ROM. v.13, p.99-102. 
RANWALA, A.P.; LEGNANI G.; MILLER, W.B. Minimizing stem elongation during spray application of gibberellins $(4+7)$ + benzyladenine to prevent leaf chlorosis in Easter lily. Horticulturae Science, Praha, v.38, p.1210-1213, 2003.

ROBLES, R. C.; MATTHES, L. A. F.; MAY, A.; DIASTAGLIACOZZO, G. Efeito do $\mathbf{G A}_{3}$ e de diferentes períodos sem hidratação após a colheita na durabilidade comercial de hastes de priprioca (Cyperus articulatus). IN: $16^{\circ}$ CONGRESSO BRASILEIRO DE FLORICULTURA E PLANTAS ORNAMENTAIS, 2007, GOIÂNIA-GO. Resumos do $16^{\circ}$ Congresso Brasileiro de Floricultura e Plantas Ornamentais. Goiânia-GO: CD-ROM. v.13, p.119122.

RUBINSTEIN, B. Regulation of cell death in flower petals. Plant Molecular Biology, New York, v.44, p.303-318, 2000.
SUBHASHINI, R.M.B.; AMARATHUNGA, N.L.K.; KRISHNARAJAH, S.A.; EESWARA, J. P. Effect of Benzylaminopurine, Gibberellic Acid, Silver Nitrate and Silver Thiosulphate, on postharvest longevity of cut leaves of Dracaena. Ceylon Journal of Science (Bio. Sci.), Peradeniya, v.40, p.157-162, 2011.

VAUGHN, K.C.; DUKE, S.O. Function of polyphenol oxidase in higher plants. Physiologia Plantarum, Lund, v.60, p.106112, 1984.

WEATHERLEY, P.E. Studies in water relations of cotton plant. I. The tield measurement of water deficits in leaves. New Phytology, London, v.49, p.81-97, 1950.

WISSEMANN, K.W.; LEE, C.Y. Polyphenoloxidase activity during grape maturation and wine production. American Journal of Enology and Viticulture, Davis, v.31, n.3, p.206211, 1980. 